\title{
Healthy Diets and Sustainable Development Goals
}

\author{
Tinatsei Gabriella Chigumete', Seema Rath², Sean James Bosman ${ }^{3}$, Sunitha Chandrasekhar \\ Srinivas ${ }^{1 *}$
}

${ }^{1}$ Faculty of Pharmacy, Rhodes University, SOUTH AFRICA.

${ }^{2}$ Hugh Kelly Fellow, Faculty of Pharmacy, Rhodes University, SOUTH AFRICA /Department of Economics, Government College, Khandola-Goa, INDIA.

${ }^{3}$ Department of English, Rhodes University, SOUTH AFRICA.

\begin{abstract}
Populations throughout the world are facing immense challenges caused by a global rise in non-communicable diseases and ongoing economic crises. Non-communicable diseases impose a large financial burden on many populations, but there continues to be an underinvestment in factors that negatively affect health. One of the targets of the Sustainable Development Goal 3 is to reduce non-communicable diseases by one third. Evidence shows that diet-related non-communicable diseases are the leading cause of death and morbidity, and that their burden is likely to increase if urgent remedial actions are not initiated on a large scale. Successful implementation and execution of diet-related health promoting policies are required to promote sustainable human development. Control measures and improved understanding of the benefits of healthy diets, as well as changes in population attitudes and practices towards healthier diets are required to reduce the prevalence of diet-related noncommunicable diseases successfully. Programs that are currently implemented have not reduced the burden of diseases significantly due to narrow goals and their limited rates of implementation.
\end{abstract}

Key words: Sustainable Development Goals, Non-communicable diseases, Diet, Health promotion, Low-andmiddle income countries.

\section{INTRODUCTION}

Diet-related non-communicable diseases (NCDs) are increasing rapidly in low- and middle-income countries (LMICs) and are one of the leading causes of morbidity and mortality. Although the World Health Organization (WHO)'s Global Action Plan has been in place for many years, the progress in national policy development in LMICs has been disproportionate. ${ }^{1}$ Transformations in food systems are rapidly increasing in most low and middle income countries. Modern food systems evolved after World War II to meet a very different set of nutritional and food requirements, and this evolution has continued through the 1990s in response to globalization. ${ }^{2}$ Globally, calories obtained from meat, diets rich in sugar, oil, salt and fats have increased during recent years, while, conversely, those from fibre-rich foods, such as whole grains, fruits and vegetables, have declined. Consumption of processed foods continues to rise rapidly in LMICs, and this nutrition transition is affecting dietary patterns and nutrient intake, which in turn influences the risk of developing NCDs. ${ }^{3}$ The rapid increase in globalization has also contributed largely to diet-related NCDs as it is followed by urbanization, population growth, and trends towards unhealthy lifestyles, which include unhealthy diets. ${ }^{4}$

This article focuses on the impact of healthy diets in relation to the burden of NCDs in LMICs. It will address the benefits of a healthy diet on the heart, which in turn may aid in reducing diet-related non-communicable diseases and their prevalence, as well as to identify sustainable initiatives that may work towards fulfilling Sustainable Development Goal 3.

\section{DIET AND NON-COMMUNICABLE DISEASES}

Nutritional epidemiology has revealed links between specific foods and nutrients or overall dietary patterns with can-
DOI: 10.5530/ijopp.9.2.7

Address for correspondence: Sunitha Chandrasekhar Srinivas,

Faculty of Pharmacy, Rhodes University, PO Box 94, Grahamstown, SOUTH AFRICA.

Phone no: +27 466038496 E-mail: s.srinivas@ru.ac.za

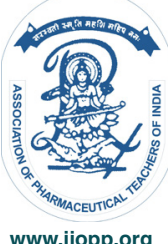


cers, cardiovascular diseases, and with intermediate consequences such as weight gain, raised blood pressure, insulin resistance and hyperglycaemia. ${ }^{5}$ Low dietary intakes of fruits, vegetables and whole grains, or a high dietary intake of salt, are individually responsible for $1.5 \%$ to more than $4 \%$ of the global disease burden. ${ }^{6}$ The poorest households in LMICs are affected the most, as evidence proves that these NCDs have largely contributed to poverty due to increasing catastrophic health expenditures. ${ }^{7}$

Obesity and overweight are risk factors that contribute to diet-related NCDs. These conditions are not only risk factors for NCDs, but major causes of illness themselves. Diet and nutritional status, including overweight and obesity, are associated with NCDs such as hypertension and diabetes. ${ }^{8}$ Diabetes and cardiovascular diseases (CVDs) are chief causes of global deaths and disability, and are largely attributable to unhealthy diets and physical inactivity. Although most CVDs could be prevented by addressing lifestyle risk factors such as unhealthy diets and physical inactivity, they remain the leading global causes of death. As highlighted by the WHO, out of the 16 million deaths under the age of 70 due to NCDs, $82 \%$ occur in LMICs and $37 \%$ are caused by CVDs. ${ }^{7}$ The global prevalence of diabetes has also risen from $4.7 \%$ to $8.5 \%$ between the years 1980 and $2014 .{ }^{9}$

Interventions to tackle diet-related NCDs by improving diets have the potential to reduce their incidence. ${ }^{10}$ The Millennium Development Goals focused primarily on the reduction of poverty, hunger and infectious diseases. The Sustainable Development Goals (SDGs) among other health targets, aim to reduce premature deaths from NCDs by one third and to end malnutrition in all of its forms. Diet-related NCDs remain at the juncture between malnutrition and NCDs. ${ }^{2}$

Increasing globalisation, urbanisation and food industry marketing tactics have brought about a nutritional transition that has resulted in a change in diets and food choices encouraging the consumption of unhealthy processed foods, especially in developing countries. ${ }^{11}$ With an increased female participation in the workforce, increasing income, and lifestyle changes, processed foods are perceived as time and money savers. ${ }^{12,13}$ Thus processed foods experience a growing acceptance by the population, while diet-related NCDs and other diseases continue to be on the rise. ${ }^{10}$

\section{BEENEFITS OF A HEALTHY DIET}

Although it is difficult to motivate people to eat healthily and to change life-long dietary habits, there are several benefits that come with a healthy diet. ${ }^{14}$ Eating healthily includes having a balanced diet that is high in vegetables, fruits and whole grains, and reducing foods that are high in fat, salt and sugar. ${ }^{15}$ Healthy eating allows one to maintain or reduce their weight to a healthy weight, which in turn reduces one's risk of NCDs such as hypertension and diabetes. Healthy eating may be achieved by taking measures to read food labels, eliminating heavily processed foods and takeaways, and by starting vegetable gardens from which fresh vegetables may be acquired. ${ }^{16}$ Diet modifications may also boost the immune system, increase bone strength and brain health, as well as increase the body's functional energy levels. ${ }^{17}$ There is, therefore need for a transformation of food systems in favour of a healthier and more sustainable diet that will facilitate the achievement of other SDGs too. ${ }^{2}$ Adoption of a new lifestyle and maintenance of these changes beyond a certain time frame is a huge challenge, especially if larger contextual issues that promote unhealthy behaviours or inhibit new behaviours remain uncurbed. ${ }^{18}$

\section{INTERVENTIONS INVOLVING NON-COMMUNICABLE DISEASES}

There have been significant efforts with regards to policies and practices that aim to reduce NCDs, but these policies suffer from numerous shortcomings. Although many policies are planned, only a handful of them are actually implemented. ${ }^{19}$ Among other weaknesses, there is a lack of funding for NCD-related initiatives. There is a lack of global advocacy and limited community participation with the current policies compared to HIV/AIDS related initiatives. ${ }^{20}$ NCDs have been neglected in developing countries partly due to a more urgent focus on infectious diseases. ${ }^{21}$ An emphasis on health promotion initiatives with the specific aim of improving NCD prevention and control, such as those which concentrate on health promotion at homes, communities and workplaces, therefore needs to be advanced. ${ }^{22}$

In a recent attempt to accelerate national efforts to address NCDs, several member States, including LMICs, have adopted the WHO specified time-bound commitments to promote healthy diet. These member States agreed to work towards the goals set for 2016. The se were to reduce both the risk factors for and the underlying social determinants of NCDs, through the implementation of interventions and policies to create health promoting environments. ${ }^{23}$ The indicators that were set as measures to reduce unhealthy diets included: adopting national policies to reduce the population's salt consumption; adopting national policies that limit saturated fatty acids and eliminate industrially produced trans fatty acids in the food; eliminating marketing of foods and non-alcoholic beverages to children; and implement- 
ing at least one recent national public awareness programme on diet. $^{24}$

The ultimate goal is to strengthen health systems to address NCDs through people-centred health promotion initiatives and universal health coverage. ${ }^{25} \mathrm{~A}$ review of government policies outlines actions in LMICs that address salt consumption, fat consumption, fruit and vegetable intake, or physical activity, revealed that $\mathrm{NCD}$ strategies were found in $47 \%$ (54 out of 116) of the LMICs reviewed. However, a smaller number of these countries had plans of action to promote healthier diets and physical activity, and only $12 \%$ of the reviewed countries proposed a policy to address all four risk factors, while $25 \%$ addressed only one of the risk factors reviewed. ${ }^{1}$

\section{POSSIBLE SETTINGS TO ADDRESS UNHEALTHY DIET}

The adoption of public health measures to increase awareness of heart healthy diets and reduce the consumption of unhealthy foods are perhaps appropriate attempts to reduce the obesity epidemic and the resultant risk of diabetes and CVDs, but it needs to form part of more complex interventions to alter dietary habits and lifestyles. ${ }^{26}$ In LMICs, hardly any connection is observed between the burden of NCDs and national policy response, suggesting the urgent need to develop inclusive policies involving all the stakeholders to improve dietary quality and physical activity. ${ }^{1}$

The WHO has recognised the workplace as a priority setting for health promotion. Workplaces directly influence the physical, mental, economic and social well-being of employees and, in turn, affect the health of these employees' families, communities and societies. ${ }^{27}$ They offer ideal settings and infrastructures to support the promotion of health of a large group of people. ${ }^{28}$ Workplaces may therefore be used as health promotion settings to increase awareness of heart healthy diets.

The Health Promoting Universities (HPUs) initiative is becoming increasingly popular around the world since 1995, since the University of Central Lancashire was launched as the first HPU. It is aimed at maximising integrative and synergistic action for sustainable public health, promoting healthy workplaces, and establishing and improving primary health care as well as encouraging wider academic interest and developments in health promotion. ${ }^{29}$ Universities that become involved in health promoting activities may obtain several benefits, including the improvement of their public image and of the university's profile, and the welfare of staff, students and the surrounding community, ${ }^{30}$ thus contributing to the fulfilment of Goal 3 of the SDGs.
Food choices are largely influenced by pricing. ${ }^{2}$ Food pricing strategies have been proposed to encourage healthy eating habits, which may in turn help to reduce the global increase in NCDs. Based on studies, declaration of taxes on carbonated drinks and foods containing saturated fat, and subsidising the prices of fruits and vegetables, would be associated with beneficial dietary change, with great potential to improve health. ${ }^{31}$

\section{HEALTH PROMOTION APPROACHES THAT MAY BE USED}

Settings based: This approach acknowledges the interrelationship between the environment and humans, for example in schools and workplaces. A settings based approach is a holistic and multi-disciplinary method which integrates action. It aims to maximize disease prevention via a "whole system" approach guided by key principles which include community participation, partnership, empowerment and equity. ${ }^{32}$ Long-term sustainability of initiatives may be achieved through integrating programs with pre-existing partnerships. ${ }^{33}$

Population based: This approach addresses the needs of diverse population groups, for instance children, women, the elderly, workers or communities. Reducing the prevalence of NCDS at population level requires that a large proportion of the population be reached with effective strategies to prevent health-related NCDs. ${ }^{34}$ For instance, a population-based approach for the prevention of childhood obesity may include initiatives that are started in schools. Results may easily be assessed, and the outcomes may also be monitored and evaluated easily due to its focused nature. ${ }^{35}$

Issues based: This approach targets a wide range of determinants of health or risk factors, such as isolating diet-related risk factors and focusing on them. An example of this approach is the WHO time-bound commitments, where indicator checklists are assigned to each measure, ensuring that progress is only measured by the successful implementation of each indicator. ${ }^{24}$

\section{CONCLUSION}

At present, diet-related NCDs are only explicitly mentioned in 1 of the 169 SDG targets, despite the many contributions improved diets would make to their attainment. To address diet-related NCDs, it is advisable that interventions tackle the root causes of poor and unbalanced diets as well as educate the population on the effects of unhealthy eating habits. Scaling up healthy diet promoting programs may be vital to reducing NCD prevalence and for sustainable human development. 


\section{ACKNOWLEDGEMENT}

The authors gratefully acknowledge Rhodes University for all of its support.

\section{CONFLICT OF INTEREST}

The author declare no conflict of interest.

\section{ABBREVIATIONS USED}

CVD: Cardiovascular disease; HIV/AIDS: Human Immunodeficiency Virus/Acquired Immunodeficiency Syndrome; LMIC: Low-and-medium income countries; NCD: Non-communicable disease; SGD: Sustainable Development Goal; WHO: World Health Organisation.

\section{REFERENCES}

1. Lachat C, Otchere S, Roberfroid D, Abdulai A, Seret FMA, Milesevic J, et al. Diet and Physical Activity for the Prevention of Noncommunicable Diseases in Low- and Middle-Income Countries: A Systematic Policy Review. PLoS Med. 2013;10(6):e1001465.

2. Hawkes C, Smith TG, Jewell J, Wardle J, Hammond RA, Friel S, et al. Smart food policies for obesity prevention. The Lancet. 2015;385(9985):2410-21.

3. World Cancer Research Fund International et al. The link between food, nutrition, diet and non-communicable diseases [Internet]. 2014 [cited 2016 Feb 9]. Available from: http://www.wcrf.org/sites/default/files/PPA_NCD_Alliance_ Nutrition.pdf

4. WHO. Global Action Plan for the Prevention and Control of NCDs 2013-2020 [Internet]. WHO. 2013 [cited 2015 Aug 19]. Available from: http://www.who.int/ nmh/events/ncd_action_plan/en/

5. Ezzati M, Riboli E. Behavioral and Dietary Risk Factors for Noncommunicable Diseases [Internet]. http://dx.doi.org/10.1056/NEJMra1203528. 2013 [cited 2016 Apr 26]. Available from: http://www.nejm.org/doi/full/10.1056/NEJMra1203528

6. WHO. WHO | Global status report on noncommunicable diseases 2014 [Internet]. 2014 [cited 2015 May 11]. Available from: http://apps.who.int/iris/ bitstream/10665/148114/1/9789241564854_eng.pdf?ua=1

7. WHO. Cardiovascular diseases factsheet [Internet]. WHO. 2015 [cited 2016 Apr 18]. Available from: http://www.who.int/mediacentre/factsheets/fs317/en/

8. Bhurosy T, Jeewon R. Overweight and Obesity Epidemic in Developing Countries: A Problem with Diet, Physical Activity, or Socioeconomic Status? Sci World J [Internet]. 2014 [cited 2015 Nov 16];2014. Available from: http://www. ncbi.nlm.nih.gov/pmc/articles/PMC4212551/

9. WHO. Global report on diabetes [Internet]. Geneva; 2016 [cited 2016 Apr 18]. Available from: http://apps.who.int/iris/bitstream/10665/204871/ 1/9789241565257_eng.pdf?ua=1

10. Cecchini M, Sassi F, Lauer JA, Lee YY, Guajardo-Barron V, Chisholm D. Tackling of unhealthy diets, physical inactivity, and obesity: health effects and cost-effectiveness. The Lancet. 2010;376(9754):1775-84

11. Malik VS, Willett WC, Hu FB. Global obesity: trends, risk factors and policy implications. Nat Rev Endocrinol. 2013;9(1):13-27.

12. Stuckler D, McKee M, Ebrahim S, Basu S. Manufacturing Epidemics: The Role of Global Producers in Increased Consumption of Unhealthy Commodities Including Processed Foods, Alcohol, and Tobacco. PLOS Med. 2012;9(6):e1001235.

13. Moodie R, Stuckler D, Monteiro C, Sheron N, Neal B, Thamarangsi T, et al. Profits and pandemics: prevention of harmful effects of tobacco, alcohol, and ultra-processed food and drink industries. The Lancet. 2013;381(9867):670-9.
14. Artinian NT. Perceived Benefits and Barriers of Eating Heart Healthy. MEDSURG Nurs. 2001;10(3):129.

15. Hawkes $\mathrm{C}$. Promoting helthy diets through nutrition education and changes in the food environment: an international review of actions and their effectiveness [Internet]. FAO Nutrition Division; 2013 [cited 2015 Aug 27]. Available from: http://www.fao.org/3/a-i3235e.pdf

16. Kita J. 9 Easy Ways To Clean Up Your Diet. Prevention. 2010;62(3):128-33.

17. Willett WC, Stampfer MJ. Current Evidence on Healthy Eating [Internet]. http:// 0-dx.doi.org.wam.seals.ac.za/10.1146/annurev-publhealth-031811-124646. 2013 [cited 2016 Apr 26]. Available from: http://0-www.annualreviews.org.wam. seals.ac.za/doi/full/10.1146/annurev-publhealth-031811-124646

18. Bloom DE, Cafiero E, Jané-Llopis E, Abrahams-Gessel S, Bloom LR, Fathima S, et al. The Global Economic Burden of Noncommunicable Diseases [Internet]. Geneva: Program on the Global Demography of Aging; 2011 Sep [cited 2015 May 10]. Report No.: 8712. Available from: https://ideas.repec.org/p/gdm/ wpaper/8712.html

19. Alwan A. Global status report on noncommunicable diseases. 2010. 2011;176.

20. Janssens B, Van Damme W, Raleigh B, Gupta J, Khem S, Soy Ty K, et al. Offering integrated care for HIV/AIDS, diabetes and hypertension within chronic disease clinics in Cambodia. Bull World Health Organ. 2007;85(11):880-5.

21. Beaglehole R, Bonita R, Horton R, Adams C, Alleyne G, Asaria P, et al. Priority actions for the non-communicable disease crisis. The Lancet. 2011;377(9775):1438-47.

22. De Jager $P$, Hofman $K$, Khan T, Volmink $H$, Jina R. Recommendations to improve the National Development Plan for Health. SAMJ. 2012;102(11):827-9.

23. Noncommunicable Diseases Progress Monitor 2015 [Internet]. WHO. [cited 2016 Apr 17]. Available from: http://www.who.int/nmh/publications/ncdprogress-monitor-2015/en/

24. WHO. Getting to 2018: Preparing for the third UN High-level Meeting on NCDs [Internet]. 2015 [cited 2016 Apr 17]. Available from: http://www.who.int/nmh/ events/2015/progress-monitor-en.pdf

25. Governance: Third UN High-level Meeting on NCDs (2018) [Internet]. WHO. [cited 2016 Apr 17]. Available from: http://www.who.int/entity/ncds/governance/ third-un-meeting/en/index.html

26. Taylor AL, Parento EW, Schmidt L. The Increasing Weight of Regulation: Countries Combat the Global Obesity Epidemic. 2014 [cited 2016 Feb 16]; Available from: http://papers.ssrn.com/abstract=2422508

27. WHO. Workplace health promotion [Internet]. WHO. 2015 [cited 2015 Apr 26]. Available from: http://www.who.int/occupational_health/topics/workplace/en/

28. Chu C, Breucker G, Harris N, Stitzel A, Gan X, Gu X, et al. Health-promoting workplaces-international settings development. Health Promot Int. 2000;15(2):155-67.

29. WHO. Types of Healthy Settings: Health Promoting Universities [Internet]. WHO. 1995 [cited 2015 May 11]. Available from: http://www.who.int/healthy_ settings/types/universities/en/

30. Cawood J, Dooris M, Powell S. Healthy universities: Shaping the future. Perspect Public Health. 2010;130(6):259-60.

31. Eyles H, Ni Mhurchu C, Nghiem N, Blakely T. Food Pricing Strategies, Population Diets, and Non-Communicable Disease: A Systematic Review of Simulation Studies. PLoS Med. 2012;9(12):1-22.

32. WHO. Types of Healthy Settings [Internet]. WHO. [cited 2015 Apr 29]. Available from: http://www.who.int/healthy_settings/types/universities/en/

33. Srivastava RK, Bachani D. Burden of NCDs, Policies and Programme for Prevention and Control of NCDs in India. Indian J Community Med. 2011;36: 57-S12.

34. Prinz RJ, Sanders MR, Shapiro CJ, Whitaker DJ, Lutzker JR. PopulationBased Prevention of Child Maltreatment: The U.S. Triple P System Population Trial. Prev Sci. 2009;10(1):1-12.

35. WHO. Population-based prevention strategies for childhood obesity: report of a WHO forum and technical meeting, Geneva, 15-17 December 2009 [Internet]. Geneva; 2010 [cited 2016 Apr 17]. Available from: http://apps.who.int/iris/ bitstream/10665/44312/1/9789241599344_eng.pdf 